\title{
Identification of Proteins That Are Developmentally Regulated During Early Cerebral Corticogenesis in the Rat
}

\author{
Daniel H. Geschwind and Susan Hockfield \\ Section of Neuroanatomy, Yale University School of Medicine, New Haven, Connecticut 06510
}

Between embryonic day 14 (E14) and embryonic day 21 (E21), the rat neopallium develops from a relatively homogeneous band of mitotic precursor cells into a complex laminated structure containing diverse classes of neurons. In order to identify some of the molecular components underlying this process, 2-dimensional PAGE was used to compare proteins expressed before cortical neurons are born (E14) with those expressed during neurogenesis and neuronal migration (E17 and E21).

This approach has permitted the identification of 15 proteins that show greater than 3-fold changes in their rate of accumulation between E14 and E21. Six proteins show consistent up-regulation, ranging from 3.2- to 10.7 -fold. Five proteins show consistent down-regulation ranging from 9to 22-fold. Four proteins that appear at E21 are not detectable on fluorograms of E14 cortex, even after long exposures, and thus are up-regulated more than 200-fold from E14 to E21 and may be considered to appear de novo. The molecular weights and isoelectric points of most of these 15 suggest that they are previously unreported, developmentally regulated proteins. Comparisons of gels of cortex to gels of lung and heart suggest that several of these proteins are enriched in brain relative to non-neural tissues. This analysis also indicates that, despite the large morphogenic changes observed during this developmental period, few proteins ( $<3 \%$ ) among the total spectrum analyzed show large changes in their rates of synthesis.

A major question in developmental neurobiology is how molecular and cellular interactions generate the anatomical complexity found in the mature mammalian cerebral cortex. While certain phenomena underlying cortical morphogenesis have been described extensively, such as the time course of neurogenesis (Angevine and Sidman, 1961; Berry and Rodgers, 1965; Hicks and D'Amato, 1968; Rakic, 1974; Luskin and Shatz, 1985; Miller, 1986) and cell migration (Ramón y Cajal, 1911; Rakic, 1972;

\footnotetext{
Received Mar. 15, 1989; revised June 7, 1989; accepted June 7, 1989.

We thank Dr. William Lutin for his invaluable help with the development of the 2-dimensional electrophoresis technique, Dr. Richard Cameron for his many helpful discussions of both experiments and the manuscript, and Dr. Linda Hendricks for helpful discussions. We also thank Dr. Fred Gorelick for his generous gift of antibody to the $\alpha$-subunit of the $\mathrm{Ca}^{2+} /$ calmodulin-dependent protein kinase II, and Hugh Fryer, Dr. Sam Zaremba, Kathleen Martin, Sandy Geschwind, and Gail Kelly for their critical reading of the manuscript. We also would like to acknowledge Dr. Luis Giuffra and Sandy Geschwind for their statistical advice. This work was supported by a grant to S.H. from the NSF (BNS-8812163). D.H.G. is supported by an NIH Medical Scientist Training Program Grant.

Correspondence should be addressed to Daniel H. Geschwind, Section of Neuroanatomy, Yale University School of Medicine, 333 Cedar St., New Haven, CT 06510 .

Copyright (C) 1989 Society for Neuroscience $0270-6474 / 89 / 124303-15 \$ 02.00 / 0$
}

Sidman and Rakic, 1973; Rakic, 1982), less is known about the identity of the molecular components that underlie these processes. Recent morphological and immunological analyses conducted by several groups indicate that cell populations are heterogeneous at early stages in corticogenesis (Shoukimas and Hinds, 1978; Levitt et al., 1981; Chun et al., 1984; Frederikson and McKay, 1988; Horton and Levitt, 1988; LeVine and Goldman, 1988). Still, few molecular markers have been identified for distinguishing among early neuronal classes or differentiative events that occur in the cerebral cortex.

Several groups have successfully approached the problem of identifying proteins correlated with early neural development in mammals by using monoclonal antibodies (Edelman, 1983; Dodd et al., 1984; Rathjen and Schachner, 1984; Hockfield and McKay, 1985; Yamamoto et al., 1986; Edmondson et al., 1988). Others have identified proteins associated with the outgrowth of axons (Skene and Willard, 1981; Szaro and Loh, 1987) and synapse formation (Baizer and Fishman, 1987) by using 2-dimensional (2-D) gel electrophoresis. The success of these methods in identifying novel developmentally regulated proteins suggested that a similar biochemical approach might be useful for identifying proteins correlated with events in early corticogenesis.

In the present study, 2-D fluorograms of a crude membrane fraction prepared from embryonic day 14 (E14), E17, and E21 rat cortical mantle were compared quantitatively to identify proteins that show large and consistent increases or decreases in their rate of accumulation during cortical morphogenesis. These ages were selected in order to analyze the cortical primordium at a time before most cortical plate neurons are born (E14) and at successive times during neuronal birth and migration (E17 and E21). A crude membrane preparation, rather than a total homogenate, was used to diminish the contribution of soluble proteins that might dominate the sample and thereby obscure the detection of changes in rarer proteins of interest (Schubert et al., 1986). Also, in vitro metabolic labeling of the intact cortical mantle was employed to restrict the analysis to proteins synthesized by cells with their cell bodies in the cortex.

This approach has permitted the identification of 15 proteins that show large increases or decreases ( $>3$-fold) in their rate of accumulation between E14 and E21. Several of these proteins appear to be enriched in brain and may be brain specific, as they are not detectable in fluorograms of heart or lung. Many of these proteins are abundant $(>0.1 \%$ protein loaded onto the first-dimension gel). However, several appear to be rare, representing $<0.001 \%$ of protein loaded onto the first-dimension gel. A preliminary report of this has appeared previously in abstract form (Geschwind and Hockfield, 1988). 


\section{Materials and Methods}

Tissue harvesting and labeling. Sprague-Dawley rats, timed-pregnant 14,17 , and $21 \mathrm{~d}(\mathrm{E} 1$ = plug date) werc obtained from Camm Research Laboratories (NJ). The fetuses were removed from ether- and pentobarbital-anesthetized mothers and kept on ice in PBS, pH 7.4. The cerebral mantle was microdissected from the rat pups with an effort to keep the cortical primordia intact and preserve local architecture. Adjoining structures such as the hippocampus, striatum, and diencephalon were not included. The meninges were removed, and the tissue rinsed thoroughly in cold $\left(4^{\circ} \mathrm{C}\right)$ Dulbecco's Minimal Essential Medium (DMEM; Gibco, NY) to remove blood and debris. Tissue from several embryos of the same age were pooled in $35 \mathrm{~mm}$ culture dishes containing $1 \mathrm{ml}$ complete DMEM and gently rocked at $37^{\circ} \mathrm{C}$ in an atmosphere of $95 \%$ $\mathrm{O}_{2} / 5 \% \mathrm{CO}_{2}$ for $30 \mathrm{~min}$, and subsequently for $30 \mathrm{~min}$ in methioninefree DMEM. Approximately $0.5 \mathrm{mCi}$ of Trans-label ${ }^{35}$ (ICN Inc., CA; specific activity $>1000 \mathrm{Ci} / \mathrm{mm}$ ), a mixture of ${ }^{35} \mathrm{~S}$-labeled methionine and cysteine, was addcd to each of the dishes and the incubation continued for $4 \mathrm{hr}$.

Crude cellular fractionation and 2-D electrophoresis. Immediately following the incubation period, the tissue was rinsed several times in icecold complete DMEM. Each sample was homogenized in $5 \mathrm{ml}$ of a 10 mM Tris buffer ( $\mathrm{pH} 7.4$ ) containing pepstatin A (1.5 mM), phenylmethylsulfonyl fluoride (1 $\mathrm{mM}), 1 \mathrm{mM} E G T A$, and $5 \mathrm{mM} \mathrm{MgCl}_{2}$, using a Dounce homogenizer. All tissue preparation steps were carried out on ice. Nuclei, unbroken cells, and debris were sedimented by centrifugation at $1400 \times g$ for $10 \mathrm{~min}$. The supernatant was collected and centrifuged at $100,000 \times g$ (Beckman SW 50.1 rotor) for $60 \mathrm{~min}$, yielding a supernatant (soluble fraction) and a pellet, which represented a crude membrane (Ames and Nikaido, 1976) or particulate fraction. The pellet was rinsed gently in homogenization buffer and frozen in liquid $\mathrm{N}_{2}$. After thawing in a modified O'Farrell lysis buffer (O'Farrell, 1975) containing $\mathrm{LKB}(\mathrm{NJ})$ ampholines of $\mathrm{pH} 4-6, \mathrm{pH} 6-10$, and $\mathrm{pH} 3.5-10$ in the ratio $2.5 / 2.0 / 0.5$, the membrane fraction was solubilized by sonication on ice (several short pulses). Specific activity (dpm/ $/ \mu$ g protein) was determined for each sample, and between $1 \times 10^{6}$ to $2 \times 10^{6} \mathrm{dpm}$ (10-50 $\mu \mathrm{g}$ of protein) was loaded onto gels that were processed for fluorography. Isoelectric focusing (IEF) and second-dimension SDSPAGE were carried out according to O'Farrell (1975) with minor modifications. IEF gels $(2 \times 130 \mathrm{~mm})$ were prerun for $15 \mathrm{~min}$ at $200 \mathrm{~V}, 15$ min at $300 \mathrm{~V}$, and then $30 \mathrm{~min}$ at $400 \mathrm{~V}$. Sample was then applied and electrophoresis continued for $16 \mathrm{hr}$ at $500 \mathrm{~V}$, followed by $2 \mathrm{hr}$ at 800 $\mathrm{V}$ and $1 \mathrm{hr}$ at $1000 \mathrm{~V}$. Following IEF, the proteins were subjected to second-dimension SDS-PAGE on $10 \%$ polyacrylamide gels. The resulting $\mathrm{pH}$ gradient ranged from approximately 4.2 to 7.0 , and apparent molecular weights $\left(M_{r}\right)$ ranged from 20 and $240\left(\mathrm{MW} \times 10^{3}\right)$. The gels were stained with Coomassie blue, processed for fluorography (Autofluor), vacuum-dried, and exposed to x-ray film (Kodak RP) at $-70^{\circ} \mathrm{C}$. The product of $\mathrm{dpm} \times \mathrm{d}$ was equalized for pairs of gels to be compared (Jacobson et al., 1986; Baizer and Fishman, 1987). Because the film was not preflashed, its response to the fluorographic image was not linear at very low or very high levels of exposure (Laskey and Mills, 1975). This potential problem was circumvented by doing multiple exposures of the same gel (Garrels, 1979; Castellucci et al., 1988) and by analyzing different sectors of the gel on different fluorograms. Actin and tubulin were quantified using short exposures $\left(6-7 \times 10^{5} \mathrm{dpm} \times\right.$ d) because they were overexposed on fluorograms at exposures required for other species $\left(4 \times 10^{6} \mathrm{dpm} \times \mathrm{d}\right)$. Long exposures $\left(1.6-2 \times 10^{7} \mathrm{dpm}\right.$ $x d)$ were used to quantify less abundant spots. Using this strategy we were able to quantify more than 800 spots on some gels.

To control for variations in incubation and dissection, as well as variations in IEF conditions, comparisons were made between samples from different developmental stages, prepared on the same day and electrophoresed in the same set of IEF gels. Each sample comprised tissue obtained from several embryos, which usually represented several litters. Thus, each fluorogram shown in a figure in this paper represents tissue pooled from several different embryos of the same age and often from more than one litter. In total, tissues from $68 \mathrm{E} 14$ and $22 \mathrm{E} 21$ embryos (each pooled into 6 dishes) and 29 E17 embryos (pooled into 4 dishes) were used. Samples from each dish were electrophoresed and analyzed in duplicate or triplicate.

Gel scanning and quantitative analysis. Fluorograms of gels were scanned, and the images were digitized using the BioImage (MI) Visage 2000 system equipped with a CCD camcra $(1024 \times 1024$ pixel resolution). To quantify the amount of each protein present, the optical density (intensity) of each protein spot (quantified relative to optical density standards) was integrated over its area. In order to identify developmentally regulated proteins, pairs of E14 and E21 fluorograms, whose exposures were equalized for the product of $\mathrm{dpm} \times \mathrm{d}$, were compared on the BioImage system. Computer analysis was used to identify proteins that showed large changes in optical density relative to all of the other proteins present (see Results, Fig. 4). As in other 2-D gel analyses (Garrels, 1979; Garrels and Schubert, 1979; Baizer and Fishman, 1987; Castelluci et al. 1988; Moya et al., 1988), the increases or decreases in a protein's optical density represent increases or decreases in the accumulation of protein synthesized during the labeling period. We refer to these changes using the terms "up-" or "downregulation" rather than increased or decreased synthesis of a protein, since the changes observed in this analysis may represent regulation of the rate of protein synthesis or protein degradation. Once spots which showed consistent changes were identified from fluorograms of E14 and E21 cortex, they were identified and quantified on fluorograms of E17 cortex, using E14 and E21 fluorograms as standards. As an internal standard, fluorograms were normalized to actin, whose rate of synthesis appears to remain relatively constant during this period (Schmitt et al., 1977; Denoulet et al., 1982). To test whether the method of standardization affected the experimental outcome, other standards were used, including normalization to 2 unknown proteins whose integrated intensity did not appear to change. Those spots that were found to show significant up- or down-regulation when normalized to actin also showed significant regulation when normalized to the 2 unidentified spots. The same was true if fluorograms were not normalized to an internal standard, but compared on the basis of total radioactivity applied to the first-dimension gels. Normalizing the fluorograms to actin gave the most conservative values of change for those spots which were up-regulated, and because actin is a well-studied protein, it was the standard used in this analysis.

Protein stains and Western blot analysis. 2-D gels loaded with between 50 and $500 \mu \mathrm{g}$ of protein were silver-stained according to Morrisey (1981) or using the Gelcode system (Enprotech Inc., MA). One cannot estimate a methionine-labeled protein's abundance simply from its fluorographic intensity because the integrated intensity of an individual protein relative to the other proteins in the sample may reflect its methionine content rather than its abundance. Thus, silver-stained gels were used to estimate the abundance of proteins that had been identified as developmentally regulated on the fluorograms. The limit of detection was considered to be $0.5 \mathrm{ng}$, which is a conservative estimate since silver stain techniques can readily detect proteins at levels less than 0.2 ng (Morrissey, 1981). If a protein was not detected when small amounts of protein were loaded, increasing amounts of protein (up to $500 \mu \mathrm{g}$ ) were electrophoresed. For example, if a protein was not detected on a gel with $50 \mu$ g protein, it was considered to represent $<0.001 \%$ of loaded protein. If the protein was not detected with the maximum protein load, it was considered to be $<0.0001 \%$ of loaded protein.

For immunological characterizations, proteins resolved by 1 -D electrophoresis were transferred to an Immobilon membrane (Millipore, MA) in a Biorad Transblot apparatus overnight at a constant current of $125 \mathrm{~mA}$, as previously described for nitrocellulose membranes (Towbin et al., 1979). The Immobilon was then incubated with antibodies overnight at $4^{\circ} \mathrm{C}$, and bound antibodies were visualized using secondary antibody coupled to alkaline phosphatase (Promega, WI).

Histology. Intact embryos were perfused transcardially with $4 \%$ paraformaldehyde (PFA) in $0.1 \mathrm{~m}$ sodium PBS (pH 7.4), and brains dissected out and postfixed in PFA for $24 \mathrm{hr}$. The telencephalon and diencephalon were embedded in gelatin (15\%)/albumin (4\%), postfixed in the same fixative, and equilibrated in $30 \%$ sucrose or in sucrose without gelatin embedding and frozen. Gelatin-embedded $50 \mu \mathrm{m}$ coronal sections were cut on a cryostat and collected and stained as free-floating sections in PBS. Twenty-five micron nonembedded sections were cut and mounted directly onto slides. Immunocytochemistry was performed as previously described (Hockfield and McKay, 1985). Some sections were stained in thionin for the determination of cytoarchitecture.

\section{Results}

Large morphogenic changes occur between E14 and E21 in the developing cerebral cortex

Between E14 and E21, the rat neopallium develops from a relatively homogeneous band of pseudostratified, mitotic precursor cells into a complex laminated structure containing diverse 
classes of neurons (Fig. 1) (Berry and Rodgers, 1965). The predominant events underlying this transformation are the birth of the majority of cortical neurons ( $>95 \%$ ) and their migration to the cortical plate, although several other events, including the ingrowth of subcortical fibers and elaboration of corticalcortical connections, also occur during this period (Wise and Jones, 1978; Levitt and Moore, 1979; Lidov and Molliver, 1982). The genesis and migration of cortical neurons is illustrated by the striking emergence of the cortical plate between E14 and E17, where postmitotic, postmigratory neurons reside (Fig. 1A). Also evident is an enlarging intermediate zone (I) through which postmitotic neurons migrate. The ventricular zone (VZ), primarily composed of mitotic precursor cells, spans almost the entire thickness of the cortical mantle at E14. However, it constitutes only a small area of the developing cortex at E17, and even less at E21. Staining with monoclonal antibody Rat-401 (Fig. 1B), a marker for radial glial cells and dividing precursor cells (Hockfield and McKay, 1985; Frederikson and McKay, 1988), reveals the appearance, between E14 and E17, of fine radial processes along which neurons migrate, as well as the decline in the density of these processes between E17 and E21.

This histological description of the early stages of rat corticogenesis provides the framework for our biochemical studies. We wanted to determine if the striking morphogenic changes seen histologically would be mirrored by equally striking changes in protein composition.

\section{In vitro labeling}

An in vitro system of labeling was used as a means for limiting the analysis to proteins synthesized by cells within the cortical mantle. This avoided labeling proteins synthesized by the afferent systems that are entering the cortex between E14 and E21. All of the observed changes in protein synthesis can therefore be interpreted in the context of local cortical events.

To determine the appropriate incubation time for labeling, tissues were labeled initially for $2,3,4,5$, and $6 \mathrm{hr}$, and the period of linear protein synthesis was determined. Figure $2 \mathrm{~A}$ shows that protein synthesis, as measured by ${ }^{35} \mathrm{~S}$ incorporation, is linear over at least the first $4 \mathrm{hr}$ of tissue labeling. Thus, unless otherwise specified, all subsequent experiments used $4 \mathrm{hr}$ continuous labeling times in order to maximize radioactivity incorporated, while remaining within the range of linear protein synthesis. Additionally, Figure $2 A$ shows that the rate of protein synthesis is several fold greater in the younger (E14) than in the older tissue (E17, E21), as has been reported by others for CNS tissue in vitro and in vivo (Barbera, 1975; Dunlop et al., 1975; White, 1981).

In order to verify that the sample preparation and crude fractionation procedures did not introduce gross artifactual changes in protein levels at the different ages studied, changes in the Rat-401 antigen and the $\alpha$-subunit of the $\mathrm{Ca}^{2+} /$ calmodulin-dependent protein kinase II, which had been shown previously to be regulated during this period, were monitored. Figure $2 B$ shows that Rat-401 immunoreactive species decrease between E14 and E21, whereas the amount of the $\mathrm{Ca}^{2+} /$ calmodulin-dependent protein kinase II increases during this period. Both are consistent with the results obtained by other investigators (Katz et al., 1985; Sahyoun et al., 1985; Frederikson and McKay, 1988; Scholtz et al., 1988). In addition, the increase in the rate of tubulin synthesis from E14 to E21 detected in the quantitative analysis of the 2-D fluorograms (see Fig. 9) is in agreement with the results reported by others (Denoulet et al., 1982; Hall et al., 1987).

\section{Quantitative analysis identifies proteins that show consistent large up- or down-regulation}

Figure 3 illustrates a typical pair of fluorograms from E14 and E21 cortical preparations. The pattern, size, and intensity of spots on each of the 2 fluorograms appear quite similar. To demonstrate that the spectrum of changes in protein synthesis between E14 and E21 were limited and to focus attention on those proteins with the largest developmental changes, the distribution of changes in all of the matched proteins from several pairs of fluorograms of E14 and E21 cortex were plotted as frequency histograms. Three histograms representing the matched spots from 3 E14-E21 comparisons are shown in Figure 4. The change in the rate of accumulation between E14 and E21 in each spot is represented on the $x$-axis by the ratio of the integrated intensities (E21/E14): a ratio of +2 means that the protein is up-regulated 2-fold from E14 to E21, and a ratio of 0.5 means that a protein is down-regulated 2-fold. Values on the $y$-axis indicate the number of proteins that showed this ratio. The mean change for proteins across all pairwise comparisons of E14 and E21 fluorograms is close to 1-fold, ranging from 0.8to 1.1 -fold. While this ratio might be anticipated on the basis of equal sample loads, the other measures of central tendency (the mode and median) are also close to 1, supporting the supposition that most proteins sampled change very little over the developmental time period examined. In almost all comparisons, approximately $95 \%$ of the spots changed less than 3-fold. Those that changed 3-fold or more lay outside the normal confidence limits of the distribution. We thus chose to focus our analysis on the significant outliers: spots that changed more than 3 -fold. This procedure allowed us to focus on changes that were significant relative to all of the other proteins in the sample. This kind of rclative comparison was important, particularly in the absence of a previous quantitative survey of cerebral cortex.

This initial data reduction narrowed the analysis to approximately 2 dozen spots that changed more than 3 -fold in 3 or more E14-E21 comparisons. To confirm the computerized matching process, the computer-analyzed images were visually inspected (see Castellucci et al., 1988). Given that the analysis now was focused on a few dozen spots, rather than several hundred, the process of image inspection and spot identification was simplified. Statistical analysis coupled with the visual screen reduced the number of proteins showing consistent changes greater than 3-fold from 25 to 11 .

\section{A small number of proteins show consistent large up- or down- regulation}

Eleven spots that passed the criteria for large developmental changes are marked on the fluorograms shown in Figure 3. Each of these proteins showed a consistent change in its rate of synthesis in every pairwise comparison between E14 and E21 fluorograms. Furthermore, the magnitude of change for each of these spots was greater than 3-fold on average and in at least 4 out of 6 individual pairwise comparisons (each done in duplicate). Also indicated are 4 spots that are detected in E21 fluorograms but not in E14 fluorograms (Fig. 3), even at very long exposures. Because they first appear between E1 7 and E21, we refer to them as appearing de novo, although at E14 they may be present at levels below our detection threshold (each is up-regulated at 

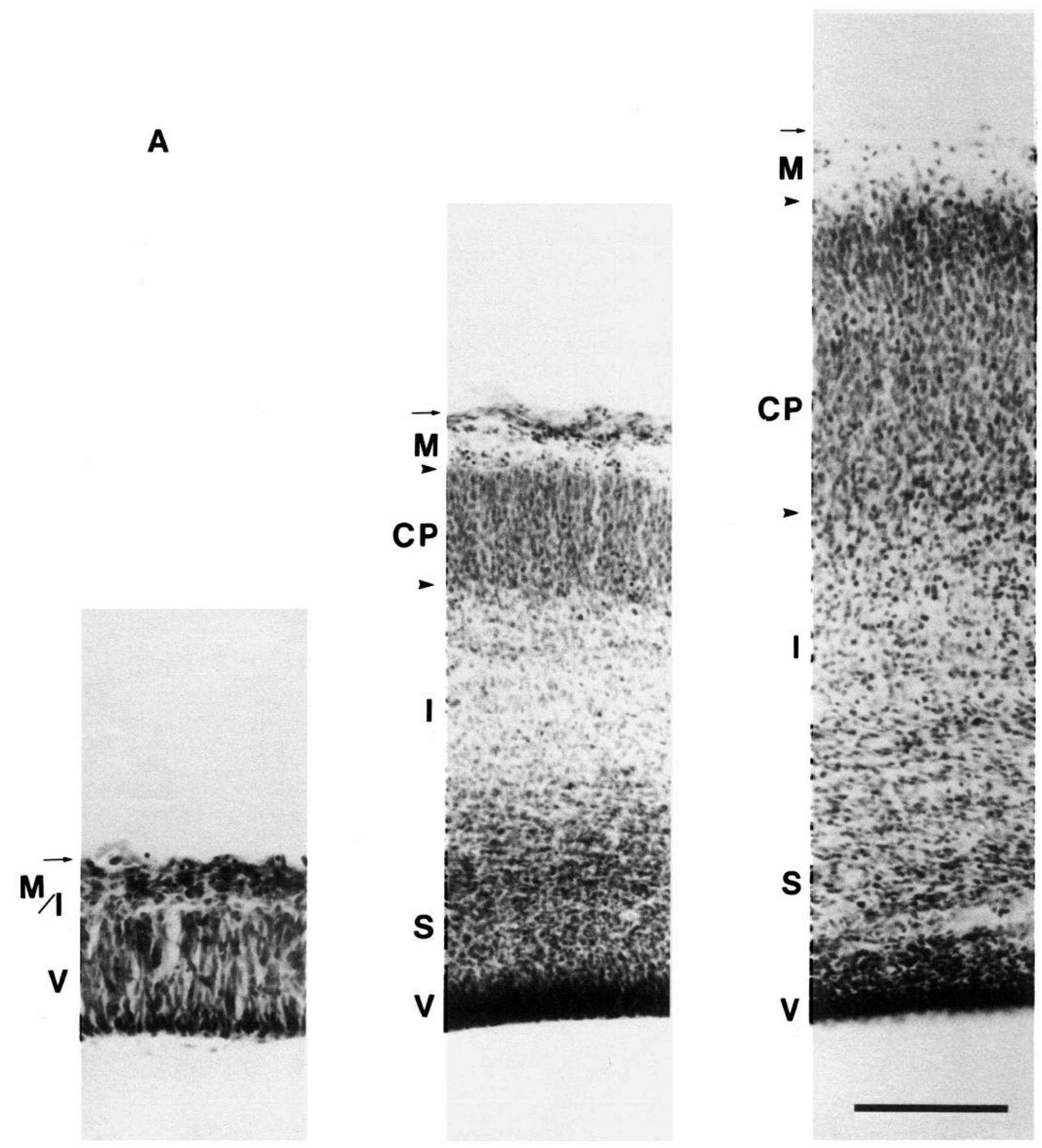

Figure 1. Sections of E14, E17, and E21 cortical primordia. $A$, Coronal sections $(25 \mu \mathrm{m})$ stained with thionin. $B$, Coronal sections $(50 \mu \mathrm{m})$ stained with the monoclonal antibody Rat-401. At E14, most Rat-401-positive processes are mitotic precursor cells, while at later stages, radial glia emerge to dominate the staining pattern. The boundaries of the cortical plate $(C P)$ are marked by the arrowheads. The small arrow indicates the pial surface. Letters to the left of each plate: marginal zone $(M)$, cortical plate $(C P)$, intermediate zone $(I)$, subventricular zone $(S)$, and ventricular zone (V). Scale bar, $100 \mu \mathrm{m}$.

least 200-fold; see Table 1). Areas of the fluorograms that include several of the regulated spots are magnified in the subsequent figures to illustrate the changes more clearly (Figs. 58). To illustrate the time course of these changes, the corre- sponding areas of fluorograms of E17 cortex are also included in Figures 5-7. Figure 5 illustrates 2 proteins, 407 (Fig. 5A) and 310 (Fig. $5 B$ ), which both show gradual up-regulation between E14 and E21. Figure 6 illustrates one protein, 182, whose syn- 

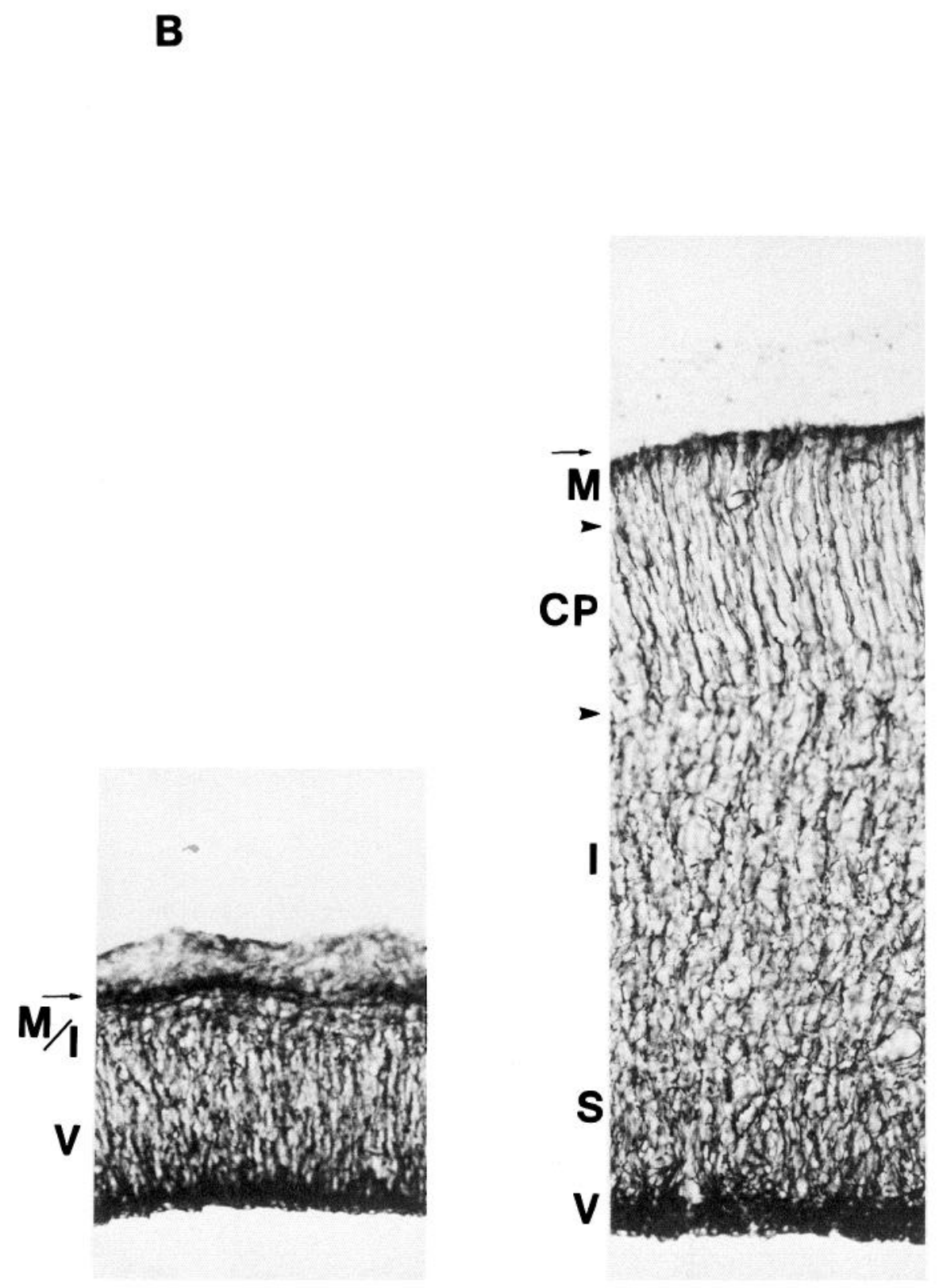

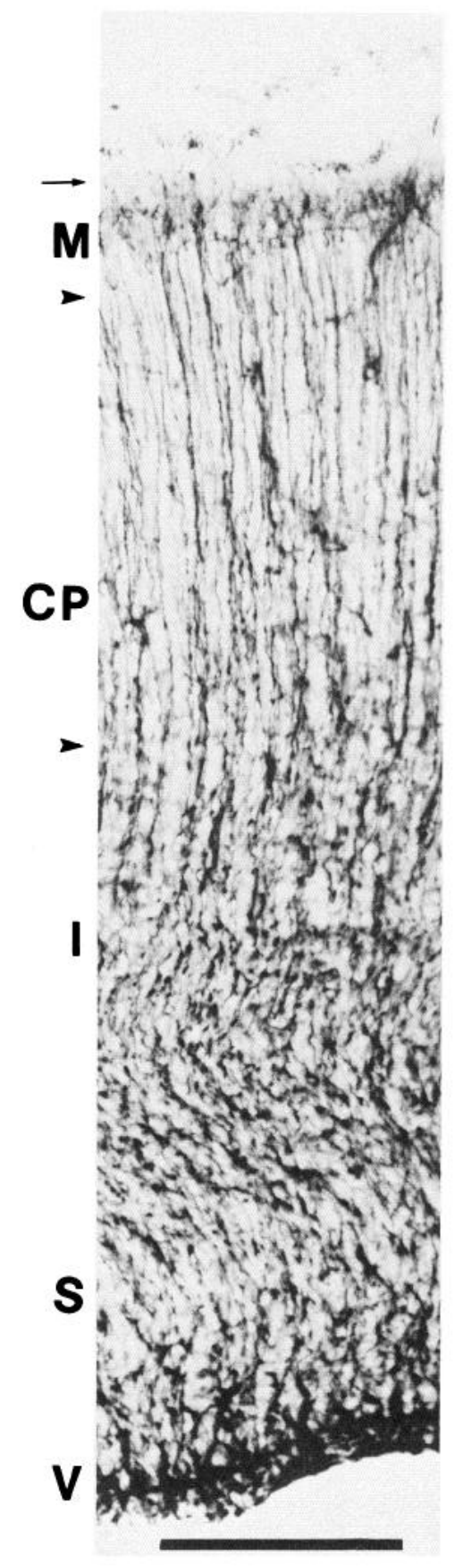

thesis appears to be down-regulated gradually between E14 and E21. Figure 7 shows several proteins that appear de novo during this period-667, 668, 800, and 802-as well as another protein, 60 , which shows a steep down-regulation between E17 and E21. The inset in Figure 7 shows the corresponding area of a fluorogram from E21 cortex labeled in vitro for $2 \mathrm{hr}$ instead of 4 hr. It demonstrates that the 2 most acidic of these proteins that appear de novo (667 and 802), appear very late in the labeling period. However, none of the other developmentally regulated proteins appears to show any relative difference in their intensity or electrophoretic mobility at shorter labeling times (not shown). Figure 8 illustrates 2 proteins that are of low fluorographic abun- dance, 28 , and 663 , whose synthesis is up-regulated between E14 and E21.

The changes in each of these developmentally regulated proteins are summarized graphically in Figure 9. The changes observed in $\alpha$ - and $\beta$-tubulin are also shown for comparison. Proteins that are up-regulated from E14 to E21 show changes ranging from 3.2- to 10.7-fold, which are greater than changes identified for $\alpha$ - or $\beta$-tubulin (1.4- and 2.7-fold, respectively). Proteins whose synthesis is down-regulated from E14 to E21 show changes ranging from 9.1- to 22.1-fold. As discussed in Materials and Methods, the type of normalization used did not alter the significance of any of the changes detected in these 
A

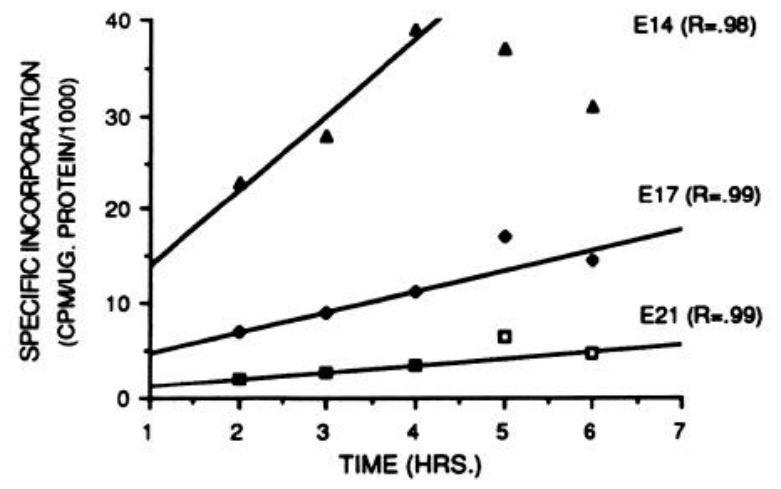

B

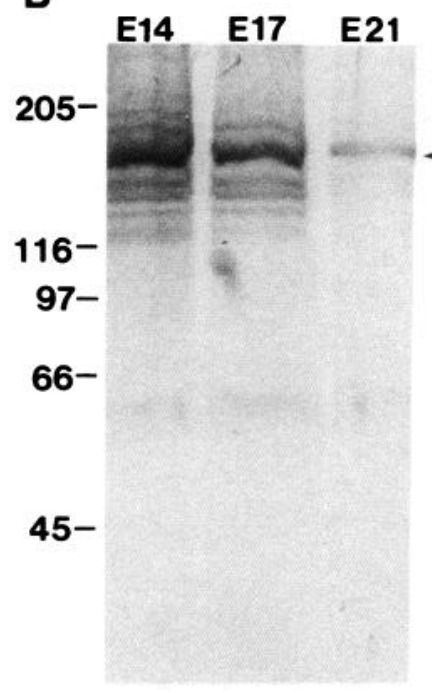

RAT-401

KIN-II

Figure 2. A, Time course of in vitro protein synthesis. Illustrated is the best-fit line through the points representing the first $4 \mathrm{hr}$ of labeling. After $4 \mathrm{hr}$, the rate of protein synthesis appears to diminish in the E14 cortex, but it remains linear up until at least $5 \mathrm{hr}$ in the E17 and E21 cortex. At least 2 samples were measured in duplicate for each time point. $B$, Western blots of the particulate fraction at E14, E17, and E21. The series of 3 blots at left were probed with the monoclonal antibody Rat-401. The series of blots at right were probed with an affinity-purified rabbit polyclonal antibody to the $\alpha$-subunit of the $\mathrm{Ca}^{2+}$ /calmodulindependent protein kinase II (Kin II; Gorelick et al., 1988). The arrowheads mark the species of interest in each blot. In the Kin II blot, the upper band represents the $\alpha$-subunit, while the lower band represents an uncharacterized immunoreactive product that appears to be abundant in embryonic cortex. Sixty micrograms of protein were loaded onto each lane.

proteins. However, it is important to emphasize the relative values, not the absolute numbers, as they varied slightly depending on the type of normalization used. The apparent isoelectric points $(\mathrm{p} I)$ and $M_{n}$ along with the direction and magnitude of the regulation, of each of these proteins are summarized in Table 1.

To confirm that the changes observed on the fluorograms are not artifacts of in vitro incubation, silver-stained gels of snapfrozen E14 and E21 cortex were also examined (Fig. 10). The extent of up- and down-regulation of these proteins corresponds very closely to that seen on the fluorograms (cf. to Fig. 3). Four
Table 1. Summary of profiles of developmentally regulated proteins

\begin{tabular}{rrllc}
$\begin{array}{c}\text { Protein } \\
\text { identity }\end{array}$ & $\begin{array}{l}\text { Apparent } \\
\text { MW }\end{array}$ & $\begin{array}{l}\text { Approx. } \\
\text { p } I\end{array}$ & $\begin{array}{l}\text { Regulation } \\
\text { (E14-E21) }\end{array}$ & $\begin{array}{l}\text { Fold-change } \\
( \pm \text { SE) }\end{array}$ \\
\hline 15 & 24 & 4.4 & Up & $10.7(4.4)$ \\
19 & 24 & 5.1 & Up & $4.6(1.7)$ \\
28 & 23 & 6.1 & Up & $3.2(.7)$ \\
310 & 64 & 6.4 & Up & $6.8(1.2)$ \\
407 & 240 & 5.4 & Up & $4.4(1.2)$ \\
663 & 24 & 5.7 & Up & $4.7(1.3)$ \\
667 & 29 & 4.7 & Up & $>200^{\circ}$ \\
668 & 30 & 4.8 & Up & $>200^{a}$ \\
800 & 30 & 4.9 & Up & $>300^{a}$ \\
802 & 29 & 4.6 & Up & $>300^{a}$ \\
60 & 28 & 5.1 & Down & $9.1(3.6)$ \\
117 & 32 & 5.9 & Down & $11.7(3.9)$ \\
137 & 34 & 5.0 & Down & $22.1(6.8)$ \\
162 & 34 & 6.4 & Down & $9.3(1.4)$ \\
182 & 44 & 5.1 & Down & $15.5(4.7)$ \\
\hline
\end{tabular}

"Spots that are not detectable on E14 fluorograms and whose fold-changes are minimum estimates based on the integrated intensity of a minimally detectable spot as described for brain-enriched proteins in the Results.

of the proteins identified in the fluorograms are illustrated more clearly in magnifications of silver-stained gels (Fig. 11). In vitro labeling detects only proteins that are synthesized during the labeling period, while silver stain detects the total steady-state pool of a protein. Thus, the changes in spot intensity between 2 ages seen using each method need not necessarily correspond to one another, although in many cases they do. These silverstained gels are also useful in estimating the abundance of a given protein. Since $50 \mu \mathrm{g}$ of protein is loaded onto the gels in Figure 10, those proteins that are very faint represent approximately $0.001 \%$ of protein (see Materials and Methods) in the sample (spot $117,668,800)$ and those that are not detected represent $<0.001 \%$ of loaded protein (162 and 802).

\section{A subset of these proteins appears to be enriched in brain}

To characterize further these developmentally regulated proteins, fluorograms of E17 cortex were compared with fluorograms of E17 or E18 and E21 heart and lung. Several of the upregulated proteins are present only in the fluorograms of cortex (Fig. 12). Spots 668 and 800, which appear between E14 and E21, are present only in cortex, as are the adjacent proteins, 667 and 802, which are found only in fluorograms of E21 cortex. Since these proteins are not detected even in a maximally exposed fluorogram of the heart or lung, their abundance in these tissues can only be estimated based on the optical density of the smallest spot detectable in our system (O.D. $=0.01-0.015$ ) and the average optical density in a maximal exposure of an appropriate fluorogram of the cortex. Using these criteria, each of these proteins is present in at least 100-fold greater amounts in the brain than in the heart or lung. Proteins 19 and 28 are at least 200 -fold more abundant in the brain than the heart or lung (Fig. 12).

Many of the proteins that are down-regulated are in areas of the gel where they are closely surrounded by many other proteins. Therefore, it is difficult to make a definitive determination at this point whether they are brain specific. However, one downregulated protein, 117 , is present only in fluorograms of cortex and is at least 200 -fold more abundant in cortex than in heart 


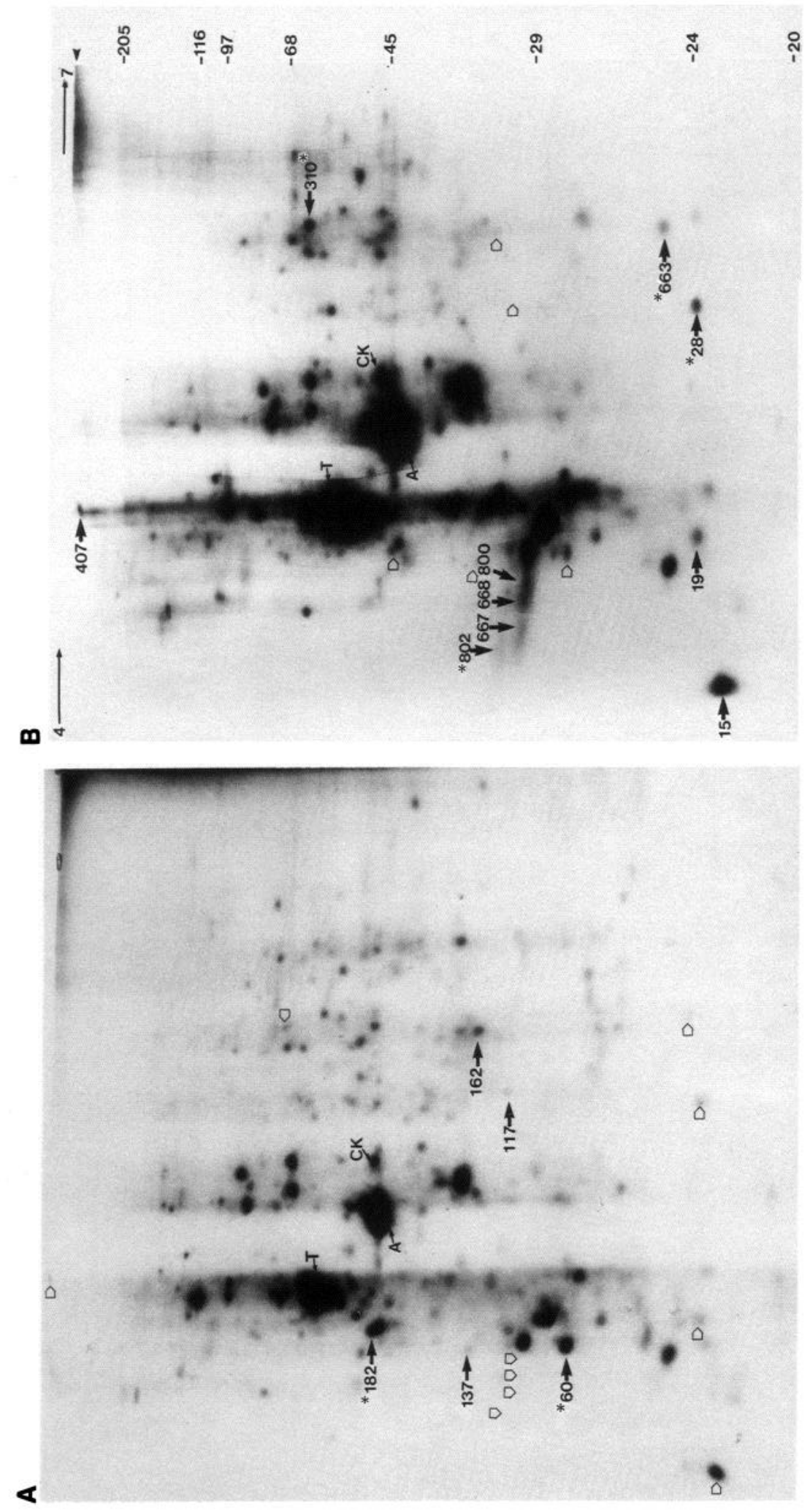

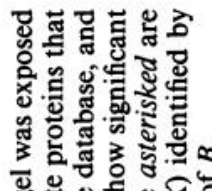

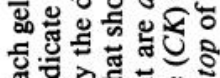
要. 额 路



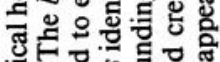

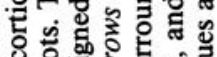
的票彭

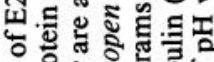

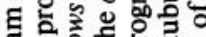


党 压 $\infty$ 장

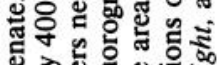

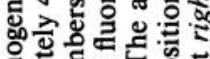
唡

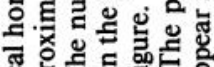

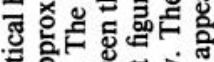
응

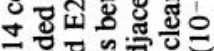

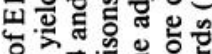
包

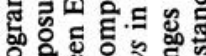
장 웡

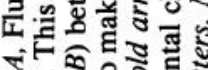
त

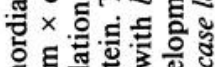

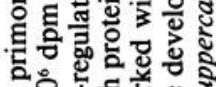

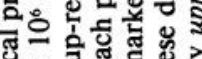

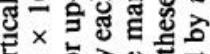

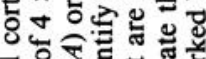
7 정 ⿶凵

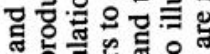

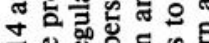
⿶凵

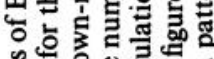
咩 运 ते . \% क.

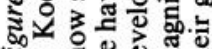

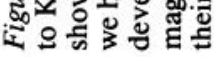




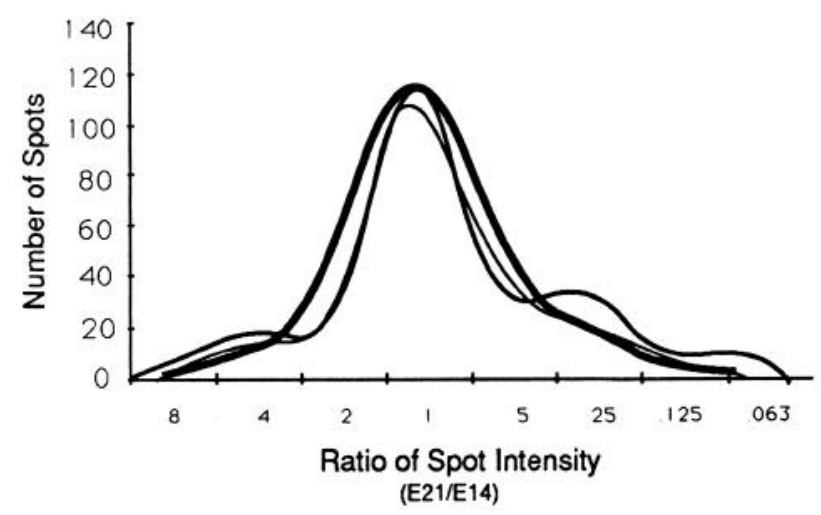

or lung. Several proteins in each class do not appear to be brain specific, including spot 162 (a down-regulated protein present in lung and heart; for location, refer to Fig. 3) and spot 407 (an up-regulated protein which appears to be present in heart and

Figure 4. Most spots do not show significant intensity changes between E14 and E21. Three histograms were plotted to show the normalized distributions of the changes in spot intensity between matched spots from 3 representative pairs of E14 and E21 fluorograms (each representing exposures of $4 \times 10^{6} \mathrm{dpm} \times \mathrm{d}$ ). Gels were matched on BioImage system and the raw data transferred to SAS, a data analysis software package, where the histograms were plotted. The histograms were traced and smoothed into curves so that several could be superimposed.

A
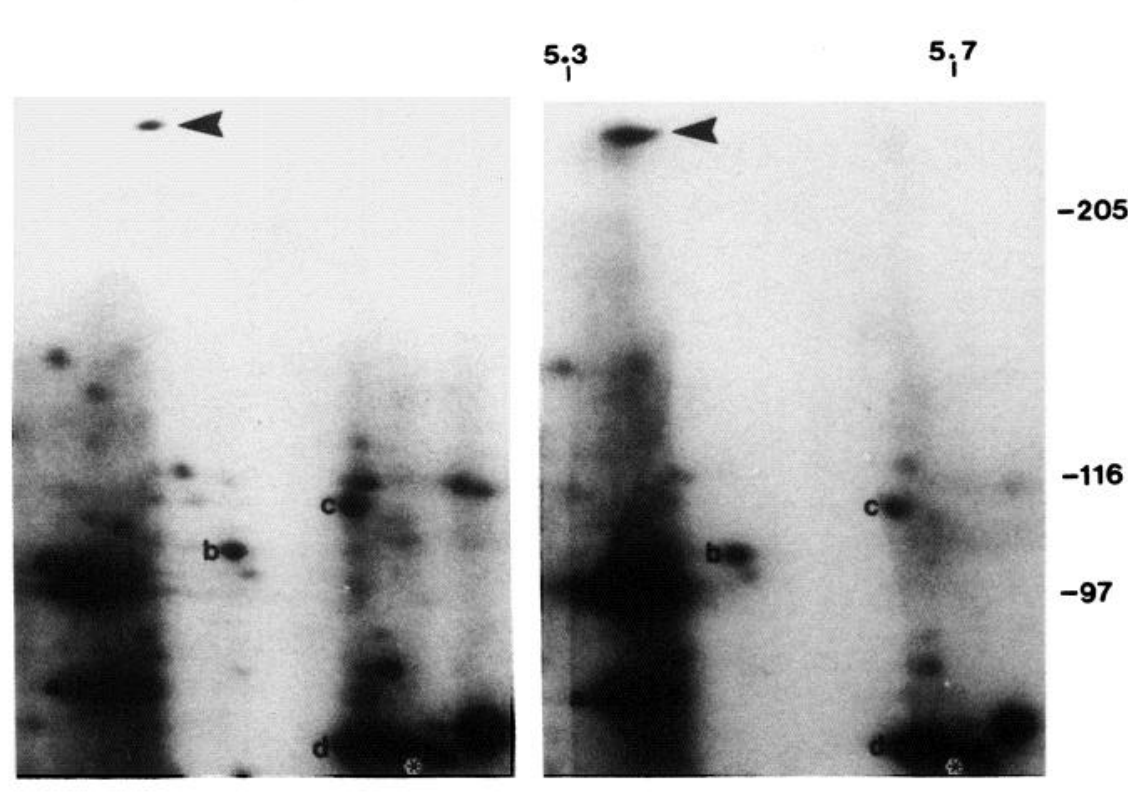

B

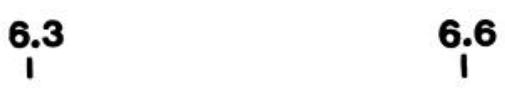

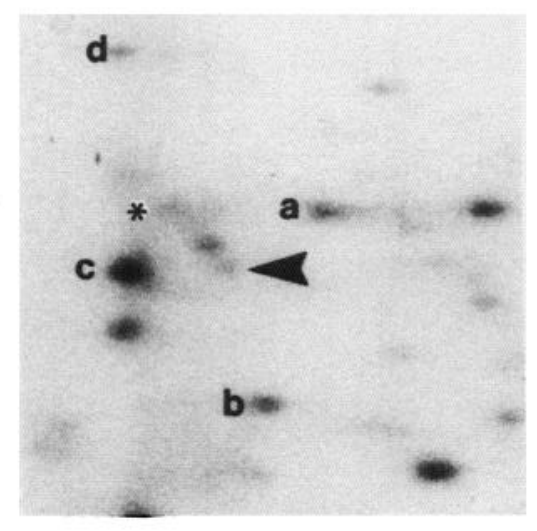

E14

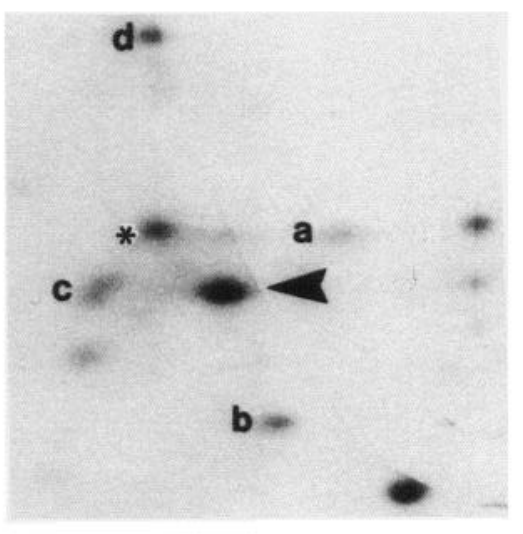

E17

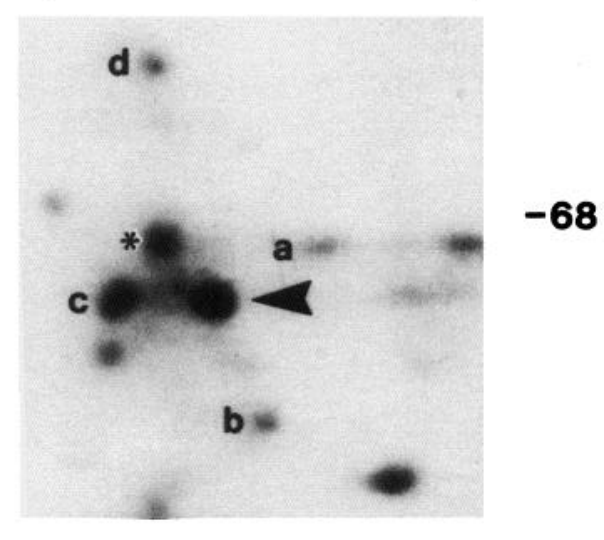

E21

Figure 5. Two proteins that are up-regulated between E14 and E21. A, Magnification of the area surrounding protein 407 (arrowhead), which was consistently up-regulated. The asterisked protein in this figure showed a consistent increase of only 2.5 -fold from E14 to E21, and thus did not reach our criterion for significance, which was 3-fold or more regulation. $B$, Magnification of the area surrounding protein 310 (arrowhead), which was consistently up-regulated. The asterisked protein increased in this series, but this change was not consistently seen. Lettered proteins in this and all figures serve as reference proteins, that is, proteins that did not consistently change from one age to the next. Molecular-weight markers $\left(\mathrm{MW} \times 10^{-3}\right)$ appear on the side, and $\mathrm{pH}$ markers appear across the top of the far-right panel. 


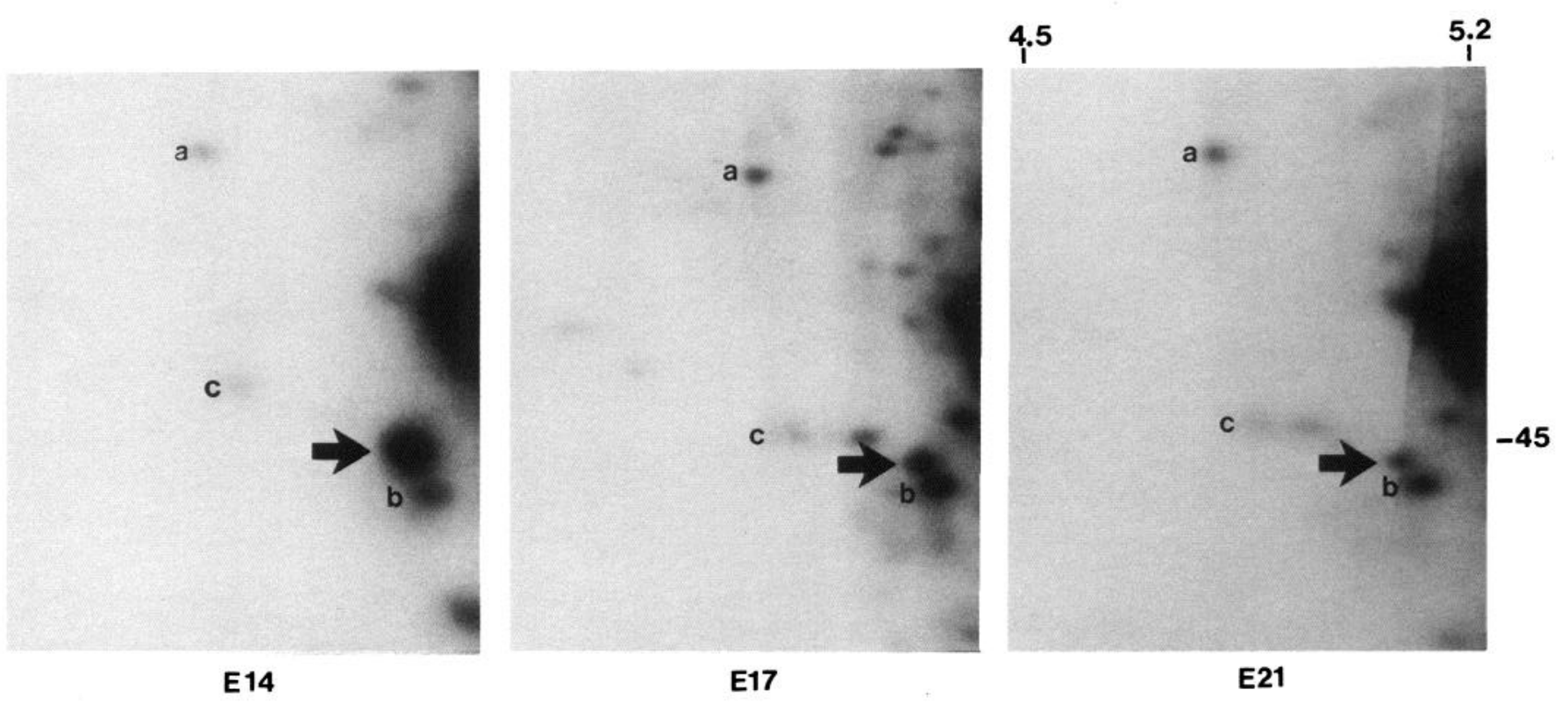

Figure 6. One protein that is down-regulated between E14 and E21. Magnification of the area surrounding protein 182 (arrow), which was consistently down-regulated.

lung; for location, refer to Fig. 3). Spot 310, which is up-regulated, is present in lung but at approximately 5 -fold lower levels than in cortex. It was not detected in heart, even at exposures 4 times longer than those shown in Figure 12.

\section{Discussion}

Using quantitative 2-D gel electrophoresis, we have identified 15 proteins that are developmentally regulated during the early stages of rat corticogenesis. Ten of these are proteins which are up-regulated and 5 are down-regulated. A subset of those which are up-regulated, proteins 19,28 , and $667,668,800$, and 802 , and one which is down-regulated, 117 , are not detected in maximally exposed fluorograms of the heart or lung. Thus, they are at least 100 -fold more abundant in brain than in these other tissues and may be brain specific.

The relative restriction of these spots to the brain makes it

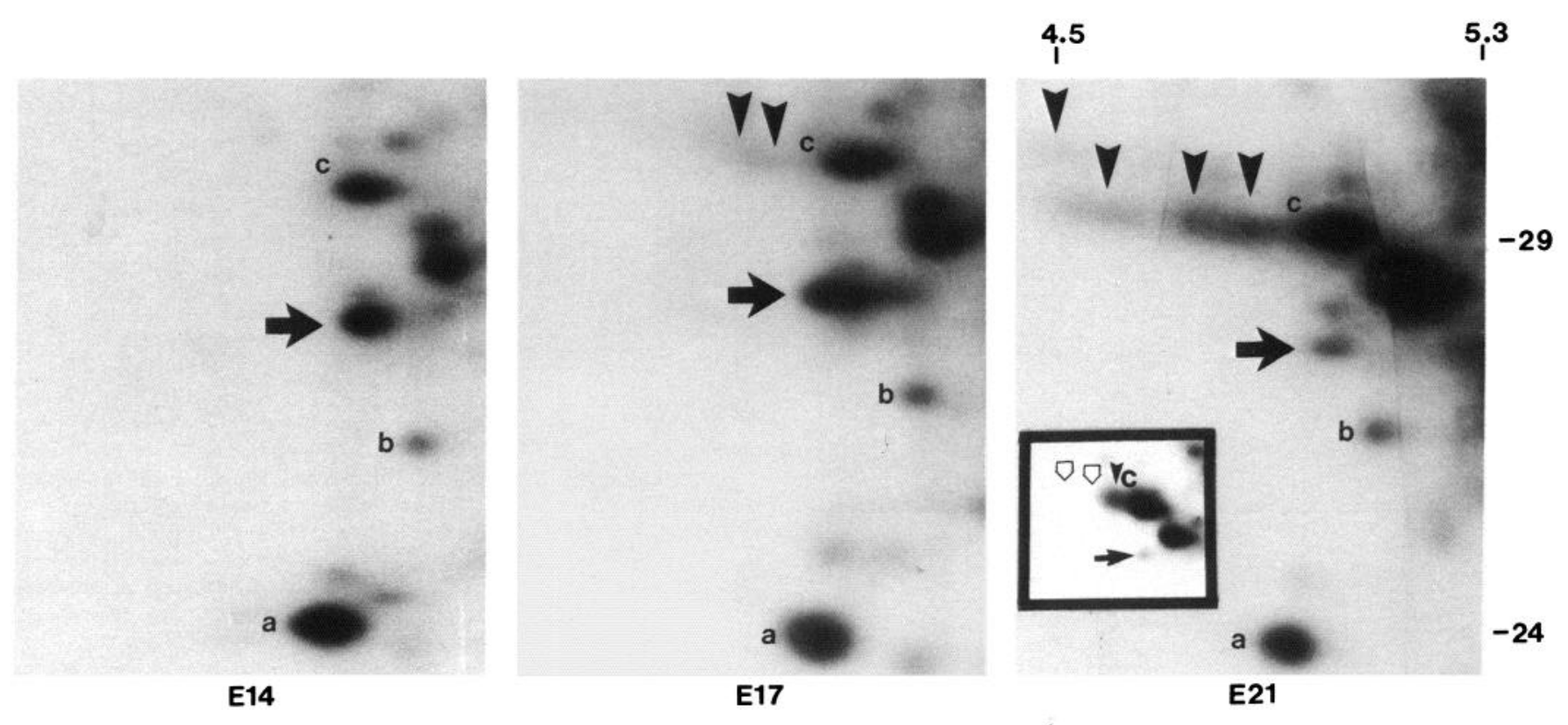

Figure 7. Several proteins that appear de novo between E14 and E21. Magnification of the area surrounding proteins $667,668,800$, and 802 (arrowheads; numbers are as indicated in Fig. 3), showing their de novo appearance between E14 and E21. Based on the intensity of a minimally detectable spot, they are up-regulated more than 200-fold between E14 and E21 (see text). Note the initial emergence of 668 and 800 between E14 and E17. Also illustrated here is protein 60 (arrow), which was down-regulated from E14 to E21. Inset, Fluorogram of E21 cortex labeled in vitro for $2 \mathrm{hr}$ but exposed so that the product of dpm $\times$ d equals that of the $4 \mathrm{hr}$ labeled fluorograms $\left(4 \times 10^{6} \mathrm{dpm} \times \mathrm{d}\right)$. This demonstrates that protein spots 667 and 802 are not detectable until very late in the labeling period (their absence is indicated by the open arrows), while the surrounding proteins are visible at levels similar to the $4 \mathrm{hr}$ labeled material. 


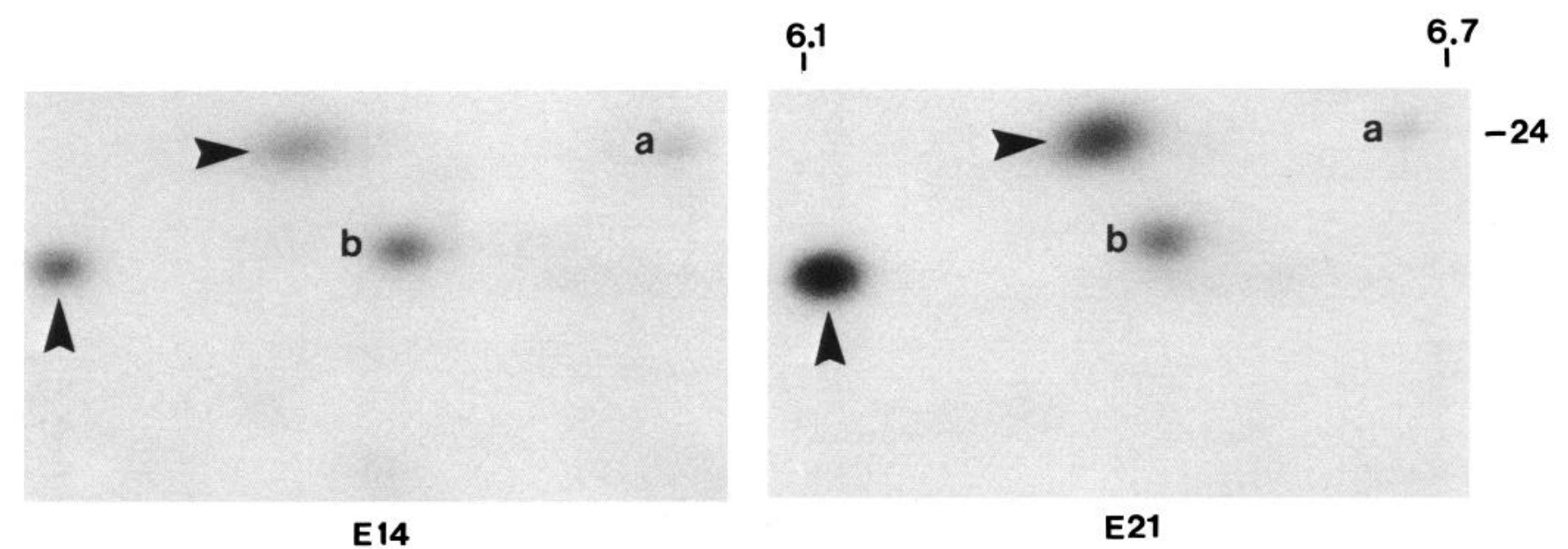

Figure 8. Two less abundant proteins that are up-regulated between E14 and E21. By using long exposures, we were able to pick out and quantify proteins whose rate of synthesis was low or had fewer than normal methionine and cystein residues and thus were fluorographically less abundant (exposure $=1.6 \times 10^{7} \mathrm{dpm} \times \mathrm{d}$ ). This figure shows the magnification of the area surrounding proteins 28 (vertical arrowhead) and 663 (horizontal arrowhead), which were both consistently up-regulated from E14 to E21.

A



B

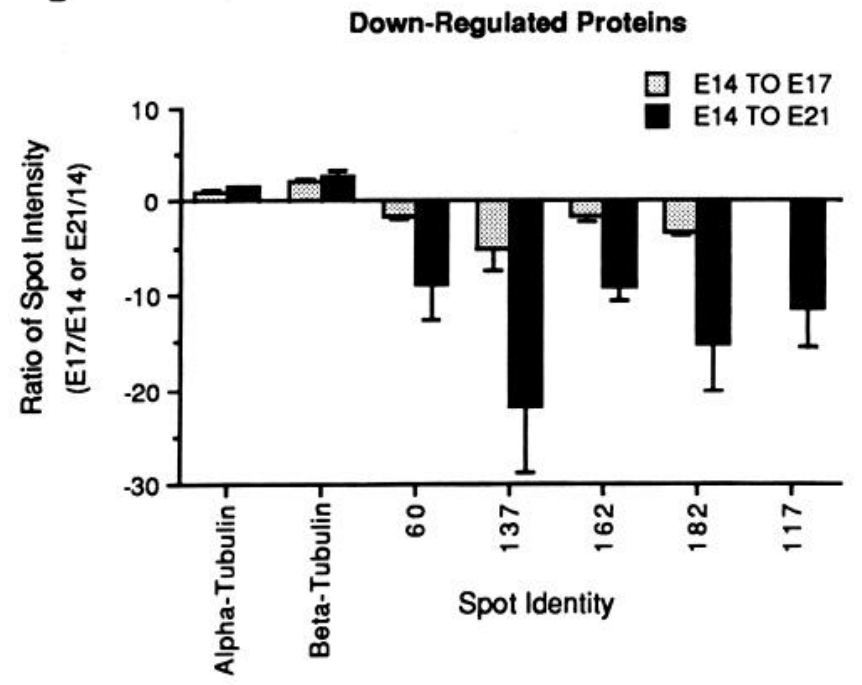

unlikely that they are related to general features of tissue or cell maturation, such as vascularization or the development of ubiquitous metabolic pathways. Since many of the up-regulated proteins, such as spots $310,407,668$, and 800 , appear to increase as early as E17, they are probably not related to oligodendrocyte or astrocyte proliferation, which takes place largely after E21 (Fedoroff and Vernadakis, 1986; Malloch et al., 1987; Frederikson and McKay, 1988; B. Friedman, personal communication). These proteins are up-regulated during the period in which the majority of cortical neurons proliferate and begin to migrate, suggesting that some of these proteins are expressed by differentiating neurons.

The 5 proteins that show large down-regulation may also participate in events that occur during early corticogenesis. Radial glia and mitotic precursor cells are decreasing in proportion to other cell populations over this period, so some of these proteins may serve as markers for specific subclasses or developmental stages of these cell populations. Several proteins have been shown to be down-regulated during normal and injury-

\footnotetext{
Figure 9. Eleven proteins show greater than 3-fold changes in their rate of synthesis between E14 and E21. $A$, Values for the changes in upregulated proteins. $B$, Values for changes in synthesis in down-regulated proteins. The changes in protein synthesis between E14 and E17 (ratio E17/E14) and between E14 and E21 (E21/E14) are normalized to actin (mean \pm SE). To facilitate comparisons between the magnitudes of the up- and down-regulated proteins, the changes observed in the downregulated proteins have been transformed from the values present in the histograms. A protein that is down-regulated 2 -fold is represented in the histogram analysis as 0.5 , whereas it is represented as -2 in this graph. Six different pairwise comparisons between E14 and E21 fluorograms, and 4 pairwise comparisons between E14 and E1 7 fluorograms were done in duplicate to calculate these values. Changes for the 3 fluorographically less abundant species $(28,663,117)$ were only analyzed for E14/E21 comparisons (5 pairwise comparisons). All of these changes were significantly different from the changes exhibited by $\alpha$ tubulin, a known protein that shows little change in its accumulation over this same time period (Mann-Whitney $U$ test or Student's $t$ test, $p<0.05)$.
} 
A

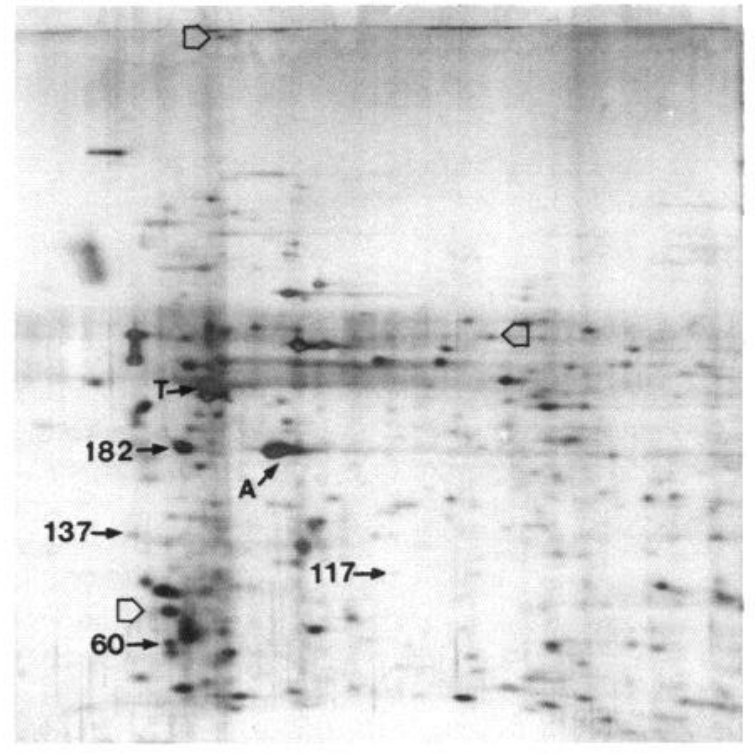

B

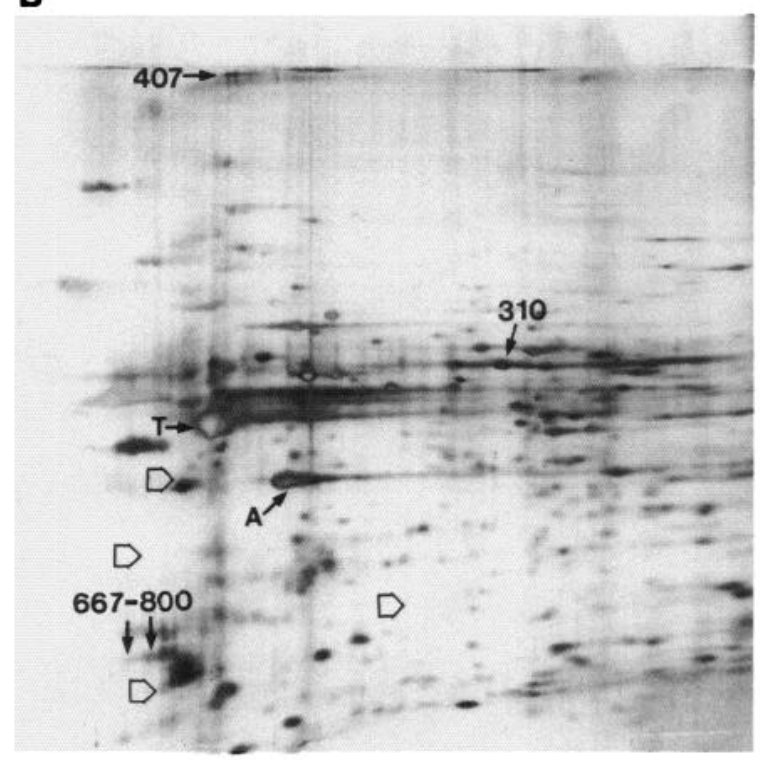

Figure 10. Silver-stained gels of E14 $(A)$ and E21 $(B)$ cortex. The bold arrows indicate proteins that showed significant down-regulation $(A)$ or up-regulation $(B)$ in the analysis of E14 and E21 fluorograms. To make comparisons between the 2 fluorograms easier, the open arrows identify proteins that show significant developmental regulation and that are marked with bold arrows in the adjacent gel. Other labels and standards as in Figure 3. Fifty micrograms of protein were loaded onto each first-dimension gel. Silver stain was done according to Morrissey (1981).

related neurite outgrowth (Szaro and Loh, 1987; Moya et al., 1988). By analogy, some of the down-regulated proteins identified in this study may comprise part of the machinery that needs to be down-regulated during development in order for a cell to elaborate axons. Another possibility is that any of these might represent proteins that are down- or up-regulated in order for a neuron to remain postmitotic.

Proteins that are not restricted to brain may also have important functions in cortical development. This is supported by experiments with N-CAM and many of the proto-oncogene products, which are present in non-neural, as well as neural tissues (Edelman, 1983; Rutishauser, 1983; Wilkinson et al., 1987; Hanley, 1988).

\section{Technical considerations}

Several details of the methodology used in this study may have contributed to the identification of a number of developmentally regulated proteins. First, since many of the interactions that occur at these early stages in a neuron's development may involve interactions that are reflected in changes at cell surfaces (Gottlieb and Glaser, 1980; Rakic, 1985), we chose an isolation procedure that simultaneously enriched for surface proteins (Ames and Nikaido, 1976) while avoiding soluble proteins, which others have found to contribute less to phenotypic variability (Schubert et al., 1986). Second, in vitro metabolic labeling allowed us to separate proteins involved in cortical neurogenesis and neuronal migration from proteins involved in another concurrent process, the ingrowth of afferents from subcortical structures. Other commonly used procedures such as silver staining or in utero metabolic labeling would have resulted in the detection of axonal proteins synthesized outside of the developing cortex, complicating the interpretation of our results. Third, restricting the analysis to one specific brain area, the cortex, may have increased our ability to identify rarer stage-specific proteins. Each distinct brain area, such as the brain stem, cerebellum, or cerebral cortex has a characteristic developmental time course, so that different brain areas develop asynchronously from one another. Thus, stage-specific differences may be blurred or lost in analyses of whole brain. This may explain why several earlier developmental studies either detected few changes during this period, or found changes in relatively abundant species such as $\alpha$-tubulin (Van Blerkom et al., 1982; Miller et al., 1987; Noguchi et al., 1984). This problem was avoided in the present study by restricting the analysis to the developing cerebral cortex in which large numbers of cells at each time period are at an approximately equivalent developmental stage.

Several lines of evidence indicate that the changes characterized in this in vitro system reflect changes that occur during in vivo corticogenesis, rather than stage-specific responses to the stress of the experimental conditions. First, the tissue is metabolically active and relatively healthy, as evidenced by linear incorporation of radioactive amino acid into protein during the period of labeling. Second, most of the developmentally regulated proteins identified fluorographically after several hours of in vitro labeling were present in similar patterns in silver-stained gels of membrane preparations from quick-frozen, unlabeled cortex. Similar results were obtained for tissue labeled in vivo (data not shown), although the amount of protein loaded onto the first-dimension gel that was necessary to see some of the rarer spots resulted in fluorograms with poor resolution. Last, judging by their molecular weight and $\mathrm{p} I$, none of the proteins identified in this study appear to be a known mammalian heat shock protein or any other characterized protein that is involved in the response to ischemia (White, 1981; Jacewicz et al., 1986).

At this point, we cannot say whether these up- or downregulations in protein accumulation represent changes in the 


\section{E14}


Figure 11. Silver-stained gels confirm the analysis of in vitro labeled tissue. Magnification of areas surrounding 2 proteins that are up-regulated $(A$ and $B)$ and 2 proteins that are down-regulated $(C$ and $D)$. One of the down-regulated proteins, $117(D)$ is of low abundance and is not visible in silver-stained gels loaded with 5 times the amount of E21 cortical protein as shown in this figure. The proteins of interest are numbered and marked with an arrow. Proteins marked with letters serve as reference spots. Fifty micrograms of protein were loaded onto each gel. rate of protein synthesis (for example, changes in the rate of transcription or mRNA stability) or reflect changes in the rate of protein degradation. In this same regard, it is also possible that since we are analyzing protein changes in the particulate fraction only, the changes in protein accumulation found here may reflect movement of a protein from membranes into another cellular compartment (cytosol or nucleus) or vice versa. Changes of this sort may have important functional implications, as evidenced by the involvement of cytosolic to membrane translocations in protein kinase $\mathrm{C}$ activation (Alkon and Rasmussen, 1988). Preliminary experiments comparing membrane and soluble fractions suggest that several of these developmentally regulated proteins may be membrane associated throughout the developmental period examined (proteins 117, 182, 407, and $667-802$ ). Thus, the changes seen in these proteins probably do not reflect movement from one cellular compartment to another. Our continuing studies are designed to characterize these regulated proteins further by producing monoclonal antibody and oligonucleotide probes that will enable us to study their anatomical and temporal distribution, as well as their regulation in more detail. New methods enabling us to use minimal quantities of protein for producing antibodies (Hockfield, 1987; Martin and Hockfield, 1988) and to obtain protein sequence from proteins resolved by 2-D gel electrophoresis (Matsudaira, 1987; Kennedy et al., 1988) should greatly facilitate this approach.

\section{Several of these proteins may be previously uncharacterized developmentally regulated proteins}

Two of the up-regulated proteins described in this study, 800 and 407 , have approximate $M_{r}$ and $\mathrm{p} I$ that correspond to rapidly transported proteins that were found to be up-regulated in the developing hamster retinofugal system (Moya et al., 1988). A protein similar to 407 has also been described in the regenerating optic nerve in Xenopus (Szaro and Loh, 1987). Both of these studies suggested that this spot corresponds to the embryonic form of N-CAM. The gel-migration pattern $\left(M_{r}\right.$ and $\left.\mathrm{p} I\right)$ and its developmental up-regulation in cortex in this study are similar to findings that have been reported for N-CAM (Hoffman et al., 1982; Rutishauser, 1983; Chuong and Edelman, 1984). However, preliminary immunological characterization suggests that 407 is not N-CAM (not shown). Definitive identification of this protein awaits further immunological characterization.

In addition to its possible equivalence to the hamster retinofugal protein mentioned above, protein 800 and its neighbors 668 , 667 , and 802 are intriguing because of their electrophoretic mobility and the appearance of the most acidic of this group, 667 and 802 , very late in the labeling period. Their streaky appearance and the increasing molecular weight concomitant with increasing $\mathrm{p} I$, suggest that these may represent posttranslational modifications of a single protein core, for example, glycosylation or phosphorylation (O'Farrell, 1975; Schubert et al., 1986). The significance of the slow accumulation of 667 and 802 relative to 668 and 800 is unknown at this point.

As far as we can tell, none of the other developmentally regulated proteins identified in the present analysis have isoelectric points and molecular weights that correspond to other known developmentally regulated proteins in the mammalian CNS (Skene and Willard, 1981; Bennett et al., 1982; Shaw and Weber, 1982; Dodd et al., 1984; Rathjen and Schachner, 1984; Darmon and Paulin, 1985; Riederer and Matus, 1985; Jacobson et al., 1986; Lenoir et al., 1986; Yamamoto et al., 1986; Baizer and Fishman, 1987; Hall et al., 1987; Miller et al., 1987; Szaro and Loh, 1987; Edmondson et al., 1988; Horton and Levitt, 1988; 

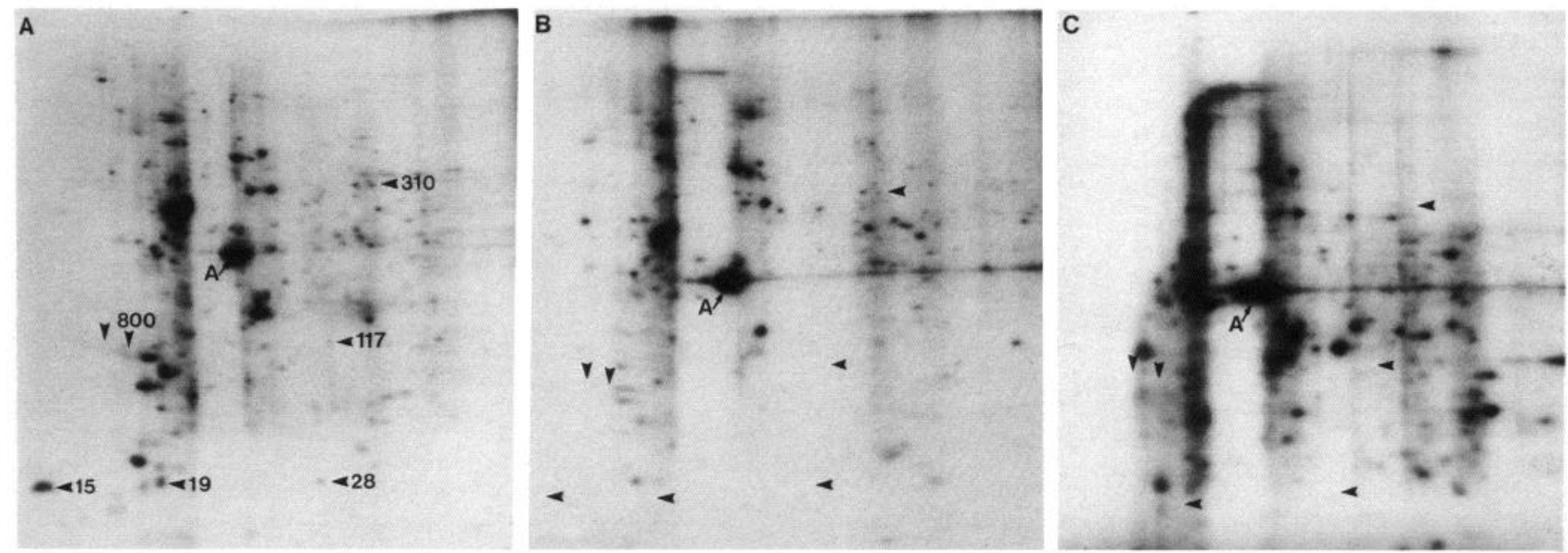

Figure 12. Some of these developmentally regulated proteins are enriched in brain. 2-D gels of E17 cortical anlage $(A)$ compared with E18 lung $(B)$ and heart $(C)$. Arrowheads specify proteins that appeared in brain, but not in heart or lung. The position of actin $(A)$ is marked in each figure. Heart and lung were metabolically labeled under in vitro conditions identical to those of cortex. Gels in $A$ and $C$ were exposed for $4 \times 10^{6} \mathrm{dpm}$ $\times \mathrm{d}$. Gel in $B$ was exposed for $1.1 \times 10^{7} \mathrm{dpm} \times \mathrm{d} . M_{r}$ and $\mathrm{p} I$ are as in Figure 3. Some of the labeled heart and lung tissue was a gift of Dr. William Lutin.

Moya et al., 1988). Therefore, it is likely that many of the upor down-regulated proteins found in this study are previously unreported, developmentally regulated molecules.

\section{Relatively few large changes accompany early cortical development}

In this analysis, the protein composition of the developing cerebral cortex changes surprisingly little when viewed in the context of the striking morphological changes that occur over this time period. Less than $3 \%$ of proteins studied showed large upor down-regulation. Most 2-D electrophoretic comparisons assay only a fraction of total cellular proteins, the question remains as to whether those analyzed can be considered to be a representative cross section. Previous 2-D gel studies have estimated that $\mathrm{pH}$ and $M_{r}$ ranges similar to those used in this report allow the resolution of $60-70 \%$ of total cellular proteins (Garrels, 1979; Duncan and McConkey, 1982; Schubert et al., 1986). Other studies using 2-D gel electrophoresis to assay protein changes that accompany development in different systems indicate that a similar percentage of changes occurs across a broad range of isoelectric points, as in separate acidic or basic fractions, alone (Garrels and Schubert, 1979; Van Blerkom et al., 1982). Given these results, our analysis may be considered to be a representative cross section of the changes that occur between E14 and E21. By analyzing a crude membrane fraction, rather than a tissue homogenate, we restricted the analysis to a substantially smaller percentage of cellular proteins. However, many abundant soluble proteins that would not show large changes may have already been subtracted from the analysis. This would lead to overestimates, rather than underestimates, of the percentage of proteins that may contribute to the emerging cellular phenotypes.

Other studies have similarly found few large changes in protein composition occurring during neuronal differentiation in vivo and in vitro. A study of the protein changes that accompany nerve growth factor-induced PC12 cell transformation found that $<5 \%$ of the proteins sampled changed more than 2 -fold (Garrels and Schubert, 1979), and even fewer changed more than 3-fold. Similarly, a study analyzing developmental changes in mRNA found that only $0.1 \%$ of the clones screened from rat brain were differentially regulated between E16 and adulthood (Miller et al., 1987). However, it is very possible that this kind of approach has not sampled rare species (1 copy of message per cell, coding for $0.005-0.001 \%$ of cellular protein) and that these rare species may contribute disproportionately to neuronal development (Chikaraishi, 1979; Milner and Sutcliffe, 1983). Also, while this analysis has focused on proteins showing large developmental regulation, the possibility must be considered that proteins changing less than 3-fold also contribute significantly to early corticogenesis.

Several of the developmentally regulated proteins identified in this study represent between 0.001 and $0.01 \%$ of protein loaded onto the first-dimension gel (for example, proteins 117, $137,162,668$, and 800 ) on the basis of silver-stain sensitivities (Morrissey, 1981). Other proteins $(162,663,667$, and 802$)$ represent $<0.0005 \%$ of loaded protein. These results, as well as estimates made by others (O'Farrell, 1975; Garrels, 1979; Duncan and McConkey, 1982; Schubert et al., 1986), indicate that 2-Dgel electrophoresis such as that used in this study can resolve proteins coded for by mRNA in the low-abundance class, approximately 1 copy per cell (Chikaraishi, 1979; Milner and Sutcliffe, 1983). Given this sensitivity, the present study, supported by the findings of others in different systems cited above, suggests that large changes in only a small percentage of total proteins accompany the morphological transformation that occurs in the developing cortex between E14 and E21.

\section{References}

Alkon, D. L., and H. Rasmussen (1988) A spatial and temporal model of cell activation. Science 239: 998-1005.

Ames, G. F.-L., and K. Nikaido (1976) Two-dimensional gel electrophoresis of membrane proteins. Biochemistry 15: 616-623.

Angevine, J. B., Jr., and R. L. Sidman (1961) Autoradiographic study of cell migration during histogenesis of cerebral cortex in the mouse. Nature 192: 766-768.

Baizer, L., and M. C. Fishman (1987) Recognition of specific targets by cultured dorsal root ganglion neurons. J. Neurosci. 7: 2305-2311.

Barbera, A. J. (1975) Adhesive recognition between developing retinal cells and the optic tecta of the chick embryo. Dev. Biol. 46: 167-191. Bennett, V., J. Davis, and W. E. Fowler (1982) Brain spectrin, a 
membrane-associated protein related in structure and function to erythrocyte spectrin. Nature 299: 126-131.

Berry, M., and A. W. Rodgers (1965) The migration of neuroblasts in the developing cerebral cortex. J. Anat. 99: 691-709.

Castellucci, V. F., T. E. Kennedy, E. R. Kandel, and P. Goelet (1988) A quantitative analysis of 2-D gels identifies proteins in which labeling is increased following long-term sensitization in Aplysia. Neuron 1: 321-328.

Chikaraishi, D. M. (1979) Complexity of cytoplasmic polyadenylated and nonpolyadenylated rat brain ribonucleic acids. Biochemistry 18 : 3249-3256.

Chun, J. J. M., M. J. Nakamura, and C. J. Shatz (1984) Transient cells of the developing mammalian telencephalon are peptide-immunoreactive neurons. Nature 325: 617-620.

Chuong, C.-M., and G. M. Edleman (1984) Alterations in neural cell adhesion molecules during development of different regions of the nervous system. J. Neurosci. 4: 2354-2368.

Darmon, M. C., and D. J. Paulin (1985) Translational activity of mRNA coding from cytoskeletal brain proteins in newborn and adult mice: A comparative study. J. Neurochem. 44: 1672-1678.

Denoulet, P., B. Edde, C. Jeantel, and F. Gros (1982) Evolution of tubulin heterogeneity during mouse brain development. Biochemie 64: $165-172$.

Dodd, J., D. Solter, and T. M. Jessell (1984) Monoclonal antibodies against carbohydrate differentiation antigens identify subsets of primary sensory neurons. Nature $311: 469-472$.

Duncan, R., and E. H. McConkey (1982) How many proteins are there in a typical mammalian cell? Clin. Chem. 28: 749-755.

Dunlop, D. S., W. Van Elden, and A. Lajtha (1975) Optimal conditions for protein synthesis in incubated slices of rat brain. Brain Res. 99: 303-318.

Edelman, G. M. (1983) Cell adhesion molecules. Science 219: 450457.

Edmondson, J. C., R. K. H. Liem, J. E. Kuster, and M. E. Hatten (1988) Astrotactin: A novel neuronal cell surface antigen that mediates neuron-astroglial interactions in cerebellar microcultures. J. Cell Biol. 106: 505-517.

Fedoroff, S., and A. Vernadakis (1986) Astrocytes: Development, Morphology, and Regional Specialization of Astrocytes, Vol. 1, pp. 3574, S. Fedoroff and A. Vernadakis, eds., Academic, New York.

Frederikson, K., and R. D. G. McKay (1988) Proliferation and differentiation of rat neuroepithelial precursor cells in vivo. J. Neurosci. 8: 1144-1151.

Garrels, J. I. (1979) Two dimensional gel electrophoresis and computer analysis of proteins synthesized by cloned cell lines. J. Biol. Chem. 254: 7961-7964.

Garrels, J. I., and D. Schubert (1979) Modulation of protein synthesis by nerve growth factor. J. Biol. Chem. 254: 7978-7985.

Geschwind, D. H., and S. Hockfield (1988) A 2-D gel analysis of proteins which are regulated during rat corticogenesis. Soc. Neurosci. Abstr. 14: 291.12.

Gorelick, F. S., J. K. T. Wang, Y. Lai, A. C. Nairn, and P. Greengard (1988) Autophosphorylation and activation of $\mathrm{Ca}^{2+} /$ calmodulin-dependent protein kinase II in intact nerve terminals. J. Biol. Chem. 263: 17209-17212.

Gottlieb, D. I., and L. Glaser (1980) Cellular recognition during neural development. Annu. Rev. Neurosci. 3: 303-318.

Hall, C., C. M. Lowndes, T. K. C. Leung, D. N. Cooper, A. M. Goate, and L. Lim (1987) Expression and developmental regulation of two unique mRNAs specific to brain membrane-bound polyribosomes. Biochem. J. 244: 359-366.

Hanley, M. R. (1988) Proto-oncogenes in the nervous system. Neuron 1: $175-182$.

Hicks, S. P., and C. J. D'Amato (1968) Cell migrations to the isocortex in the rat. Anat. Rec. 160:619-634.

Hockfield, S. (1987) A Mab to a unique cerebellar neuron generated by immunosuppression and rapid immunization. Science 237: 6770.

Hockfield, S., and R. D. G. McKay (1985) Identification of major cell classes in the developing mammalian nervous system. J. Neurosci. 5: 3310-3328.

Hoffman, S., B. C. Sorkin, P. C. White, R. Brackenbury, R. Mailhammer, U. Rutishauser, B. A. Cunningham, and G. M. Edelman (1982) Chemical characterization of a neural cell adhesion molecule (NCAM) purified from embryonic brain membranes. J. Biol. Chem. 257: $7720-7728$.
Horton, H. L., and P. Levitt (1988) A unique membrane protein is expressed early on limbic system axons and cortical targets. J. Neurosci. 8: 4653-4661.

Jacewicz, M., M. Kiessling, and W. A. Pulsinelli (1986) Selective gene expression in focal cerebral ischemia. J. Cerebr. Blood Flow Metab. 6: $263-272$.

Jacobson, R. D., I. Virag, and J. H. P. Skene (1986) A protein associated with axon growth, GAP-43, is widely distributed and developmentally regulated in the rat CNS. J. Neurosci. 6: 1843-1855.

Katz, F., L. Ellis, and K. H. Pfenninger (1985) Nerve growth cones isolated from fetal rat brain III. Calcium-dependent protein phosphorylation. J. Neurosci. 5: 1402-1411.

Kennedy, T. E., M. A. Gawinowicz, A. Barzilai, E. R. Kandel, and J. D. Sweatt (1988) Sequencing of proteins from two-dimensional gels by using in situ digestion and transfer of peptides to polyvinylidene difluoride membranes: Application to proteins associated with sensitization in Aplysia. Proc. Natl. Acad. Sci. USA 85: 7008-7012.

Laskey, R. A., and A. D. Mills (1975) Quantitative film detection of ${ }^{3} \mathrm{H}$ and ${ }^{14} \mathrm{C}$ in polyacrylamide gels by fluorography. Eur. J. Biochem. 56: $335-341$

Lenoir, D., E. Battenberg, M. Kiel, F. E. Bloom, and R. J. Milner (1986) The brain-specific gene $1 \mathrm{~b} 236$ is expressed postnatally in the developing rat brain. J. Neurosci. 6: 522-530.

Leong, S. F., and J. B. Clark (1984a) Regional enzyme development in rat brain-enzymes associated with glucose utilization. Biochem. J. 218: 131-138.

Leong, S. F., and J. B. Clark (1984b) Regional enzyme development in rat brain-enzymes of energy metabolism. Biochem. J. 218: 139145 .

LeVine, S. M., and J. E. Goldman (1988) Embryonic divergence of oligodendrocyte and astrocyte lineages in developing rat cerebrum. J. Neurosci. 8: 3992-4006.

Levitt, P., and R. Y. Moore (1979) Development of the noradrenergic innervation of neocortex. Brain Res. 162: 243-259.

Levitt, P., M. L. Cooper, and P. Rakic (1981) Coexistence of neuronal and glial precursor cells in the cerebral ventricular zone of the fetal monkey: An ultrastructural immunoperoxidase analysis. J. Neurosci. 1: 27-39.

Lidov, H. G. W., and M. E. Molliver (1982) An immunohistochemical study of serotonin neuron development in the rat: Ascending pathways and terminal fields. Brain Res. Bull. 8: 389-430.

Luskin, M. B., and C. J. Shatz (1985) Neurogenesis of the cat's primary visual cortex. J. Comp. Neurol. 173: 611-631.

Malloch, G. D. A., J. B. Clark, and F. R. Burnet (1987) Glial fibrillary acidic protein in the cytoskeletal and soluble protein fractions of the developing rat brain. J. Neurochem. 48: 299-306.

Martin, K. A., and S. Hockfield (1988) A monoclonal antibody that identifies large diameter primary afferents in the spinal cord. Soc. Neurosci. Abstr. 14: 279.6.

Matsudaira, P. (1987) Sequence from picomole quantities of proteins electroblotted onto polyvinylidene diffuoride membranes. J. Biol. Chem. 262: 10035-10038.

Miller, F. D., C. C. G. Naus, G. A. Higgins, F. E. Bloom, and R. J. Milner (1987) Developmentally regulated rat brain mRNAs: Molecular and anatomical characterization. J. Neurosci. $7 ;$ 2433-2444.

Miller, M. W. (1986) Effects of alcohol on the generation and migration of cerebral cortical neurons. Science 233: 4308-4311.

Milner, R. J., and J. G. Sutcliffe (1983) Gene expression in rat brain. Nucleic Acids Res. 11: 5497-5520.

Morrissey, J. H. (1981) Silver stain for proteins in polyacrylamide gels: A modified procedure with enhanced uniform sensitivity. Anal. Biochem. 117: 307-310.

Moya, K. L., L. I. Benowitz, S. Jhaveri, and G. E. Schneider (1988) Changes in rapidly transported proteins in developing hamster retinofugal axons. J. Neurosci. 8: 4445-4454.

Noguchi, S., S. I. Ogata, M. Sato, and T. Muramatsu (1984) Stagespecific polypeptides in the developing mouse brain as demonstrated by two-dimensional gel electrophoresis. J. Biochem. 96: 881-886.

O'Farrell, P. H. (1975) High resolution two-dimensional gel electrophoresis of proteins. J. Biol. Chem. 250: 4007-4021.

Rakic, P. (1972) Mode of cell migration to the superficial layers of fetal monkey neocortex. J. Comp. Neurol. 145: 61-84.

Rakic, P. (1974) Neurons in the rhesus monkey visual cortex: Systematic relation between time of origin and eventual disposition. Science 183: $425-427$.

Rakic, P. (1982) Early developmental events: Cell lineages, acquisition 
of neuronal positions, and areal and laminar development. In Neurosciences Research Program Bulletin: Development and Modifiability of the Cerebral Cortex, P. Rakic and P. S. Goldman-Rakic, eds., pp. 439-461, MIT Press, Cambridge, MA.

Rakic, P. (1985) Contact regulation of neuronal migration. In The Cell in Contact: Adhesions and Junctions as Morphogenetic Determinants, G. M. Edelman and J. P. Thiery, eds., pp. 67-91, Neurosciences Research Foundation, New York.

Ramón y Cajal, S. (1911) Histologie du système nerveux de l'homme et des vertèbres, 2:847-861, Maloine, Paris, reprinted Institute Ramón y Cajal, Madrid (1972).

Rathjen, F. G., and M. Schachner (1984) Immunocytological and biochemical characterization of a new neuronal cell surface component ( $\mathrm{Ll}$ antigen) which is involved in cell adhesion. EMBO J. 3: $1-10$.

Riederer, B., and A. Matus (1985) Differential expression of distinct microtubule-associated proteins during brain development. Proc. Natl. Acad. Sci. USA 82: 6006-6009.

Rutishauser, U. (1983) Molecular and biological properties of a neural cell adhesion molecule. Cold Spring Harbor Symp. Quant. Biol. 68: 501-514.

Sahyoun, N., H. LeVine, S. K. Burgess, S. Blanchard, K.-J. Chang, and P. Cuatrecasas (1985) Early postnatal development of $\mathrm{Ca}^{2+} / \mathrm{cal}-$ modulin-dependent protein kinase II in rat brain. Biochem. Biophys. Res. Commun. 132: 878-884.

Schmitt, H., I. Gozes, and U. Z. Littauer (1977) Decrease in levels and rates of synthesis of tubulin and actin in developing rat brain. Brain Res. 121: 327-342.

Schultz, W. K., C. Baitinger, H. Schulman, and P. T. Kelly (1988) Developmental changes in $\mathrm{Ca}^{2+} / \mathrm{calmodulin}^{2}$-dependent protein $\mathrm{ki}$ nase II in cultures of hippocampal pyramidal neurons and astrocytes. J. Neurosci. 8: 1039-1051.

Schubert, D., B. Brass, and J.-P. Dumas (1986) Protein complexity of central nervous system cell lines. J. Neurosci. 6: 2829-2836.

Shaw, G., and K. Weber (1982) Differential expression of neurofilament triplet proteins in brain development. Nature 298: 277-279.

Shoukimas, G. M., and J. W. Hinds (1978) The development of the cerebral cortex in the embryonic mouse: An electron microscopic serial section analysis. J. Comp. Neurol. 179: 795-830.

Sidman, R. L., and P. Rakic (1973) Neuronal migration, with special reference to the developing human brain: A review. Brain Res. 62 : $1-35$.

Skene, J. H. P., and M. Willard (1981) Axonally transported proteins associated with axon growth in rabbit central and peripheral nervous systems. J. Cell Biol. 89: 96-103.

Szaro, B. G., and Y. P. Loh (1987) Changes in axonal transport and glial proteins during optic nerve regeneration in Xenopus laevis. In Current Topics in Developmental Biology, pp. 217-254, Academic New York.

Towbin, H., T. Staehelin, and J. Gordon (1979) Electrophoretic transfer of proteins from polyacrylamide gels to nitrocellulose sheets: Procedure and some applications. Proc. Natl. Acad. Sci. USA 76:4350 4354.

Van Blerkom, J., R. Janzen, and M. N. Runner (1982) The patterns of protein synthesis during foetal and neonatal organ development in the mouse are remarkably similar. J. Embryol. Exp. Morphol. 72 97-116.

White, F. P. (1981) The induction of "stress" proteins in organ slices from brain, heart, and lung as a function of postnatal development. J. Neurosci. I: 1312-1319.

Wilkinson, D. G., J. A. Bailes, and A. P. McMahon (1987) Expression of the proto-oncogene int-1 is restricted to specific neural cells in the developing mouse embryo. Cell 50: 79-88.

Wise, S. P., and E. G. Jones (1978) Developmental studies of thalamocortical and commissural connections in the rat somatic sensory cortex. J. Comp. Neurol. 178: 187-208.

Yamamoto, M., A. M. Boyer, J. E. Crandall, M. Edwards, and H. Tanaka (1986) Distribution of stage-specific neurite-associated proteins in the developing murine central nervous system recognized by a monoclonal antibody. J. Neurosci. 6: 3576-3594.

Yoshida, Y., and T. Takahishi (1980) Compositional changes in soluble proteins of cerebral mantle, cerebellum, and brain stem of rat brain during development. Neurochem. Res. 5: 81-96. 